\title{
Assessment of recent epidemiological trends in peptic ulcer perforation patients in an eastern indian tertiary hospital
}

\author{
Bikash Chandra Ghosh, ${ }^{1}$ Ambar Gangopadhyay ${ }^{2}$, Gautam Ghosh ${ }^{3}$ \\ ${ }_{1,2}$ Associate Professor, Department of General Surgery, R. G. Kar Medical College Kolkata, ${ }^{3}$ Professor and Head, \\ Department of General Surgery, R. G. Kar Medical College,Kolkata
}

Background: Peptic Ulcer perforation is one of the most important and dreaded complication of peptic ulcer disease. In-spite of recent therapeutic management options available, it is still life threatening catastrophe. Sudden release of gastric and duodenal content in peritoneal cavity leads to devastating sequence of events which if not properly managed may lead to death. Age and Gender adjusted analysis of incidence, morbidity and mortality and the effect of ulcerogenic medications, addictions and H. Pylori infection in prognosis were studied here. Postoperative outcomes were also assessed after giving same type of treatments (Preoperative resuscitation, Graham's Patch repair, and postoperative care) given by same surgical team. Aims and Objectives: The aims and objectives of this study were to investigate the latest trends of incidence, presentation, morbidity and mortality of benign perforated gastro-duodenal ulcer among the various age groups of population and to further study the risk factors associated with these events and study the association of addiction, ulcerogenic medications and H. Pylori infection. Materials and Methods: This observational descriptive study was conducted in R.G.Kar Medical College, Kolkata between the periods from January 2016 to June 2017 among 102 patients. Results: In this study of 102 patients $97 \%$ were male patients, maximum number of patient were from the age group $15-30$ years (45.1\%).86.3\% were from low socio- economic status and $40.2 \%$ residing in urban slum. Maximum number of patients presenting within $72 \mathrm{hrs}(71 \%)$ having zero mortality. Seventy four percent of patients presented with shock if came between 4-5 days with $17.39 \%$ mortality. Patient presenting after 5 days had mortality of $75 \%$ and shock was $100 \%$ finding. Size $<1 \mathrm{~cm}$ having $1 \%$ mortality but if size is $>1 \mathrm{~cm}$ then mortality was $>50.5 \%$. Conclusion: Perforated peptic ulcer is common among males in second and third decade of their life with patients living in rural and urban slum commonly affected. Most common predisposing factors for PPU among younger population were addictions like smoking or alcohol intake. Among the elderly patients, intake of ulcerogenic medications like NSAID and steroids was the most common predisposing factor for PPU. Among patients of non-NSAID associated PPU, Helicobacter pylori infection was the major cause in the pathogenesis of PPU.

Key words: Peptic; Perforation; Epidemiology; Prognostic factors; Helicobacter pylori; NSAID.

\section{INTRODUCTION}

Perforated peptic ulcer is a surgical emergency and is found to be associated with short-term mortality in near about $30 \%$ of patients and morbidity in up to $50 \%{ }^{1}$
Access this article online

\section{Website:}

http://nepjol.info/index.php/AJMS

DOI: 10.3126/ajms.v9i6.20858

E-ISSN: 2091-0576

P-ISSN: $2467-9100$
Global variations in demography, socioeconomic status, prevalence of Helicobacter pylori infections, and prescription medications make investigation into risk factors associated with peptic ulcer difficult. Perforated peptic ulcer presents as an acute abdominal emergency condition, with localized 
or generalized peritonitis and a high risk for further development of sepsis and death. Early diagnosis is very much essential, but the clinical signs can be obscured in elderly people or immunocompromised patients, thus delaying further confirmation of diagnosis. Imaging plays an important role in diagnosis, as does early resuscitation, including initiation of treatment with suitable antibiotics. Appropriate risk assessment and selection of therapeutic options becomes important to address the risk for morbidity and mortality.

Epidemiology of peptic ulcer disease and its Complications: Peptic ulcer disease affects nearly 4 million of global population yearly. ${ }^{2}$ Its complications are reported approximately in 10-20\% among these patients and ulcer perforation is noted in near about $2-14 \% .{ }^{3,4}$ Perforation of the peptic ulcer is the second most important and dreaded complication of peptic ulcer disease. In early decades of the twentieth century ulcer perforation incidence increased significantly, and there was an epidemic of ulcer perforations situated in the duodenum of middle-aged men. ${ }^{5,6}$ Peptic ulcer disease includes perforation, bleeding, and obstruction. Although perforations are secondary to bleeding in frequency (about 1:6 ratio), they represent the most common indication for emergency surgical intervention for peptic ulcer. Overall progress in medical management of peptic ulcer disease has made obstruction from recurrent ulcer scarring a rare event, and further addition of newly developed endoscopic techniques and transarterial embolization has reduced the need for emergency surgery for bleeding ulcers. ${ }^{7}$ Pathogenesis, causes, and risk factors for perforation: Although an overall imbalance between the protective and the ulcerogenic factors was reported in ulcer formation process, the reasons why some patients' ulcers perforate and others do not is not understood. Development of ulcer involves infection (Hpylori), mucosal barrier injury (e.g. use of drugs), and increased production of hydrochloric acid. The precise risk estimates and contribution of each factor are still poorly understood. ${ }^{8}$ Only about one third of patients affected by perforated peptic ulcer reported a previous history of or current known peptic ulcer disease at the time of diagnosis. Some patients develop very small $(<5 \mathrm{~mm})$ perforations without any large mucosal defects, which suggests that ulcer size is unrelated to perforation risk, whereas others might develop large mucosal defects with perforation several centimeters in size.

Clinical assessment and diagnosis: Patients with perforated peptic ulcer disease might present with severe, sudden-onset pain in epigastric region, which can become generalized. The peritonitis which results from acid exposure can present as abdominal board-like rigidity. Comparatively the clinical picture might be less clear in obese patients, immunocompromised individuals, patients on steroids, those with a reduced level of consciousness, elderly people, and pediatric population. In these situations, the clinical history and examination might be non-specific, prompting additional requirement of imaging and laboratory studies to further rule out differential diagnoses. Only two-thirds of patients present with frank peritonitis, ${ }^{9}$ which might partially explain the diagnostic delay in some patients.

In spite of the widespread therapeutic application of gastric anti-secretory agents and eradication therapy, the incidence of perforated peptic ulcer (PPU) showed minor changes. However, there has been a significant change in the epidemiological reports of perforated peptic ulcer in the west over the last two decades. Previously, most patients were middle aged, with a ratio of 2:1 of male: female. With time, there has been a steady increase in the age of the patients suffering from this life threatening complication. In spite of availability of modern therapeutic management tools it is still a life-threatening catastrophe. Perforation is more common indication now a day than bleeding for surgical intervention. As with bleeding ulcer, NSAID and/or aspirin use have been inextricably linked with perforated PUD, especially in the elderly population. Ulcer perforation was a lethal condition until surgical intervention was introduced. Mikulicz was the first to introduce the suturing method for a perforated gastric ulcer in $1880,{ }^{10}$ and suture is still the most common available option for ulcer perforation. Although occasionally nonsurgical approach can be considered in the stable patient without peritonitis in whom radiological studies document a sealed perforation.

Surgical options for perforated duodenal ulcer are simple patch closure, patch closure and HSV (Highly Selective Vagotomy), or patch closure and Vagotomy plus Drainage. At present simple patch closure is the most commonly performed procedure for perforated peptic ulcer. Options for prevention of peptic ulcer perforation must be considered on the two etiological factors: Treatment of H.pylori infection and use of Nonsteroidal anti-inflammatory drugs (NSAIDS). Present study was conducted to assess the latest trends of incidence, presentation and mortality of benign perforated gastroduodenal peptic ulcer.

\section{Aims and objectives}

Our study aimed to investigate the latest trends of incidence, presentation and mortality of benign perforated gastro-duodenal peptic ulcer among the various age groups and to study the risk factors associated with these events. Objectives of this study were to investigate the epidemiological trends in incidence of perforated peptic ulcer (PPU) with respect to age and gender and to further analyze the epidemiological trends in mortality of perforated peptic ulcer (PPU) with respect to age and gender and to analyze the effects of ulcerogenic 
medications, addictions and H.Pylori infection on incidence of perforated Peptic Ulcer.

\section{MATERIALS AND METHODS}

This study was carried out in the Department of Surgery, R.G.Kar Medical College and Hospital from the period January 2016 to June 2017. All patients admitted in General surgical ward (Emergency Department) presenting with diagnosis of peptic ulcer perforation and further operated were included. A total of 102 patients were included in this study. All patients below the age of 12 years, with a diagnosis of malignant neoplasia, (confirmed by histological findings after biopsy or resection) and presenting with traumatic perforations were excluded.

Pre-operative parameters studied were age, gender demographic profile, risk factors(including history of intake of NSAIDS, history of smoking and/or intake of alcohol), any co-morbid medical illness and clinical findings(including features of peritonitis, pulse, B.P, temperature, respiratory rate...etc) were noted. Postoperative parameters studied were histopathological findings [Histologic visualization of $H$. pylori using routine hematoxylin-eosin stains or special stains (e.g., silver, Giemsa, Genta stains)], morbidity (including post-operative pain, duration of hospital stay, time to return to work, wound infection and wound dehiscence) and mortality.

\section{Statistical analysis}

This was a retrospective descriptive observational single centre study. At the end of the study, the data was compiled, tabulated and the statistical analysis was carried out with the help of Standard Statistical methods and Software.

\section{RESULTS AND ANALYSIS}

In this study 102 cases of Perforated Peptic Ulcer who attended surgical emergency room at R.G.Kar Medical College and Hospital were selected over the period of one and half year from January 2016 to June 2017.

In this study most of the patients with perforated peptic ulcer were in the age group of 15 to 30 years constituting near about $45 \%$ of the total number of cases followed by cases belonging to the age group of 31 to 45 years. The youngest patient in this study was 14 years and the oldest patient was 72 year old (Figure 1)

In this study maximum numbers of patients were found to be male $(97 \%)$ and the females constituted only $3 \%$. (Table 1)

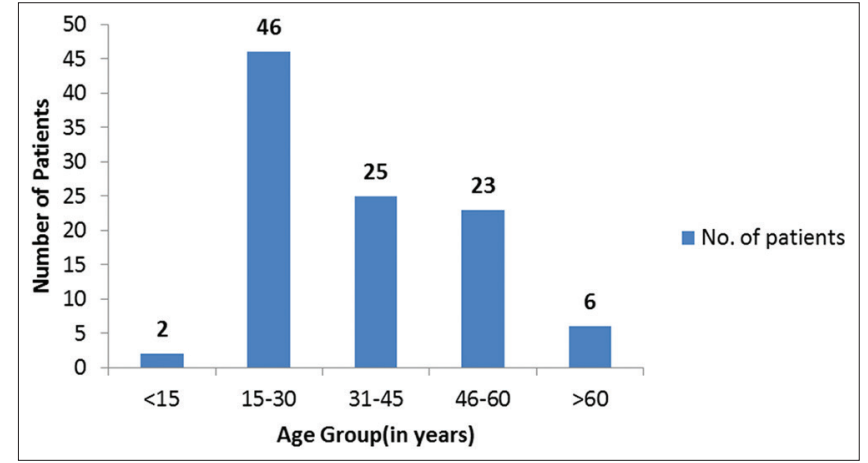

Figure 1: Distribution of Incidence of patients with PPU by Age group

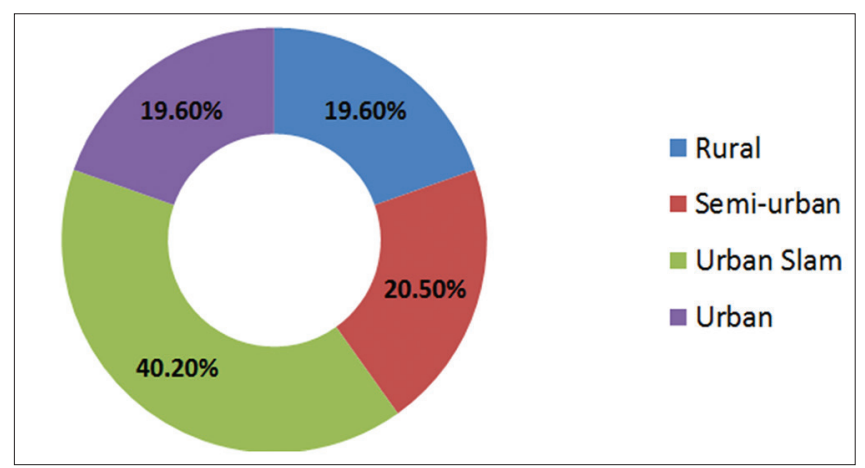

Figure 2: Distribution of Incidence of patients with PPU by Geographical area

\begin{tabular}{|c|c|c|}
\hline Gender & No. of patients & Percentage \\
\hline Male & 99 & 97.05 \\
\hline Female & 3 & 2.95 \\
\hline Total & 102 & \\
\hline
\end{tabular}

\begin{tabular}{lcc}
$\begin{array}{l}\text { Table 2: Distribution of patients by } \\
\text { socioeconomic status }\end{array}$ & \\
\hline Socio-economic status & No. of patients & Percentage \\
\hline Upper & 00 & 00 \\
Lower & 88 & 86.3 \\
Middle & 14 & 13.7 \\
\hline
\end{tabular}

In this study maximum participant patients were found to be residing in the Urban Slums (about $40 \%$ of the study patients). Figure 2 shows the distribution of the patients according to the various geographical areas. Most of the patients belonged to low socio-economic background as shown in Table 2.

In this study we tried to focus correlation between the delay in clinical presentation with the presence of shock and subsequent mortality rate among the patients and it was reported that all the patients presenting after more than 5 days of onset of initial sign and symptoms presented

Asian Journal of Medical Sciences | Nov-Dec 2018 | Vol 9 | Issue 6 
with shock and mortality rate of $75 \%$ was noted among these patients (Figure 3). Maximum percentage of patients presented within 3 days of onset of their symptoms with almost negligible patients followed by shock and subsequent mortality (Table 3).

In this study, very little number of patients presented without the features of peritonitis or gas under diaphragm in skiagram (3\% and $3 \%$ respectively) as depicted in Table 4.

In this study we also found that most common ulcerogenic medications associated with PPU were NSAID and it was seen more in elderly population. All the females presented with PPU, had a history of intake of NSAID with steroids. All the cases of PPU above the age of 60 years had a history of intake of NSAIDs. The Table 5 shows the distribution of use of ulcerogenic medications in regards to age and gender among the patients of PPU. We also reported no history of any ulcerogenic medications in 69 patients.

In this study it was noticed that most common form of addiction noted among our patients of PPU was Smoking either in the form of Tobacco or Cannabis (Ganja). This was followed by addiction to both Smoking and Alcohol. Patients (particularly male) of younger age group were addicted to smoking. The Table 9 shows the distribution

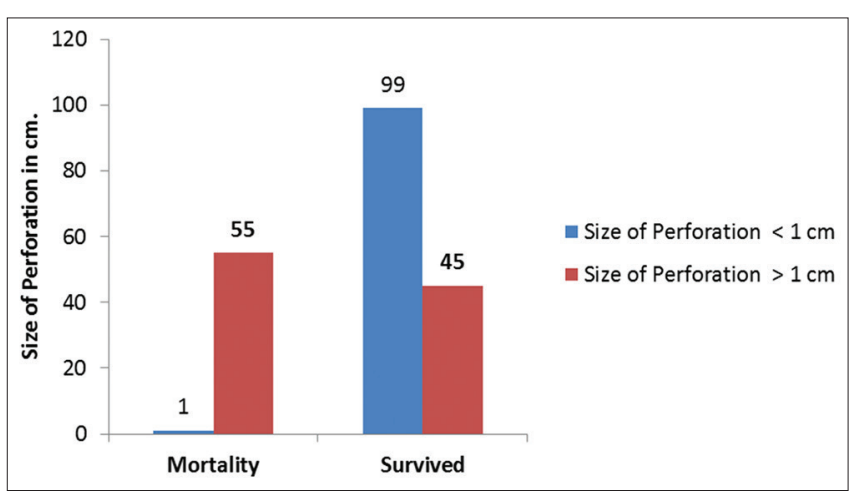

Figure 3: Relation of Size of perforation with Mortality

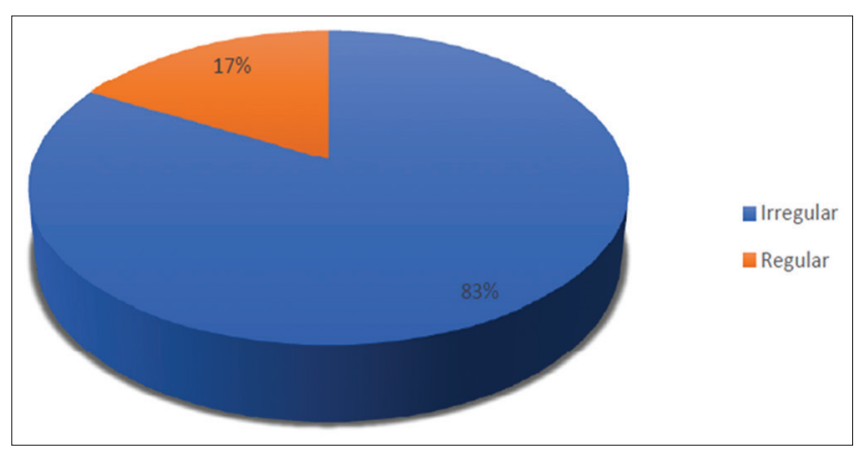

Figure 4: Distribution of Dietary Habits among patients of PPU of various types of addictions in patients with PPU in respect to age. No history of addictions was reported in 12 patients. (Table 6)

In this study, it was noticed that among all of the patients of PPU, $83 \%$ of patients had irregular dietary habits as depicted in Figure 4. Past history of Peptic Ulcer disease (PUD) was noted in $53 \%$ of as seen in Figure 5.

\section{Distribution of $H$ pylori infection (by HPE)}

Table 7 shows the distribution of $H$ pylori infection (by HPE) in the patients of PPU. It was noted that $94 \%$ of the patients in the age group of 15 to 45 years tested positive for Hpylori infection and it was mostly uncommon in age the group of 46 to 60 years and completely absent in elderly age group $>60$ years. All the female patients were negative for the infection of Hpylori.

Among all of the patients in this study, most common post-operative outcome (about $75 \%$ of patients) was uneventful. Also, maximum numbers of deaths were reported in the patients with age above 60 years. Post operative complications were seen in 21 patients (20.5\%). Table 8 shows the distribution of patients of PPU with respect to postoperative event, age and gender.

In the patients showing complications in post-operative period, most common complication was Lower Respiratory Tract Infection (LRTI) followed by Acute Respiratory Distress Syndrome (ARDS) along with wound infection. (Figure 6)

Table 9 shows the distribution of duration of hospital stay among patients of PPU. In this study, we found that patients with younger age group of 15 to 45 years had comparatively shorter hospital stay as compared with patients above the age of 45 years. Total duration of hospital stay varied from 4 days to 18 days. Longer duration of stay was associated with the post-operative complications.

\section{DISCUSSION}

In our study, 102 patients of PPU who presented in Emergency department of R.G.Kar Medical College and Hospital between the periods of January 2016 to June 2017 were studied. PPU was found to be more common in males as compared to females with a male: female ratio of 33: 1 which was widely inconsistent from other studies like in Lee FY et al (ratio of 5.2: 1) ${ }^{2}$; Nuhu et al (ratio of 4.85: 1$)^{3}$ and Meena et al (ratio of 10:1). ${ }^{4}$

However, all studies related to perforative peritonitis showed a male preponderance, although the male to female ratio varied from 1.34:1 to 7:1.5,6,10 Patel and Baria showed that 
Table 3: Distribution of patients with respect to delay of presentation, presence of shock and subsequent mortality

\begin{tabular}{lccc}
\hline Time of presentation (in days) & No. of patients (with percentage) & Patients presented with shock & Mortality among the patients \\
\hline <1 Day & $4(3.9)$ & 0 & 0 \\
1 to 3 Days & $71(69,6)$ & 1 & 0 \\
4 to 5 Days & $23(22.6)$ & 17 & 4 \\
>5 Days & $4(3.9)$ & 4 & 3 \\
\hline
\end{tabular}

\section{Table 4: Patients with features of peritonitis and presence of gas under diaphragm in skiagram}

\begin{tabular}{lcc} 
No. of patients & Present (with \%) & Absent (with \%) \\
\hline Features of peritonitis & $99(97)$ & $3(3)$ \\
Gas under diaphragm & $101(99)$ & $3(3)$ \\
\hline
\end{tabular}

\begin{tabular}{|c|c|c|c|c|c|c|c|c|c|c|c|c|}
\hline \multirow[t]{2}{*}{ Ulcerogenic medications } & \multirow{2}{*}{$\begin{array}{l}\text { Age (in years } \\
\text { Gender }\end{array}$} & \multicolumn{2}{|c|}{$<15$} & \multicolumn{2}{|c|}{$15-30$} & \multicolumn{2}{|c|}{$31-45$} & \multicolumn{2}{|c|}{$46-60$} & \multicolumn{2}{|c|}{$>60$} & \multirow[t]{2}{*}{ Tota } \\
\hline & & $\mathbf{F}$ & M & $\mathbf{F}$ & M & $\mathbf{F}$ & M & $\mathbf{F}$ & M & $\mathbf{F}$ & $M$ & \\
\hline NSAIDS & & 0 & 0 & 2 & 0 & 4 & 0 & 19 & 0 & 4 & 0 & 29 \\
\hline Steroids & & 1 & 0 & 0 & 0 & 0 & 0 & 0 & 0 & 0 & 0 & 1 \\
\hline NSAIDS + Steroids & & 0 & 0 & 0 & 0 & 0 & 0 & 0 & 1 & 0 & 2 & 3 \\
\hline Total & & 1 & 2 & & & 4 & 20 & & & 6 & & 33 \\
\hline
\end{tabular}

\begin{tabular}{|c|c|c|c|c|c|c|}
\hline $\begin{array}{l}\text { Age groups } \\
\text { (in years) }\end{array}$ & $<15$ & $15-30$ & $31-45$ & $46-60$ & $>60$ & Total \\
\hline \multicolumn{7}{|l|}{ Addictions } \\
\hline Smoking & 1 & 23 & 14 & 13 & 2 & 53 \\
\hline Alcohol & 0 & 3 & 2 & 1 & 0 & 6 \\
\hline Smoking + Alcohol & 0 & 12 & 7 & 3 & 0 & 22 \\
\hline Glue Sniffing & 1 & 8 & 0 & 0 & 0 & 9 \\
\hline Total & 2 & 46 & 23 & 17 & 2 & 90 \\
\hline
\end{tabular}

\begin{tabular}{|c|c|c|c|c|c|c|}
\hline $\begin{array}{l}\text { Age groups } \\
\text { (in years) }\end{array}$ & $<15$ & $15-30$ & $31-45$ & $46-60$ & $>60$ & Total \\
\hline \multicolumn{7}{|l|}{ HPE infection } \\
\hline \multicolumn{7}{|l|}{ Male } \\
\hline Positive & 2 & 43 & 23 & 6 & 0 & 74 \\
\hline Negative & 0 & 2 & 2 & 17 & 4 & 25 \\
\hline \multicolumn{7}{|l|}{ Female } \\
\hline Positive & 0 & 0 & 0 & 0 & 0 & 0 \\
\hline Negative & 0 & 0 & 0 & 1 & 2 & 3 \\
\hline
\end{tabular}

\begin{tabular}{|c|c|c|c|c|c|c|}
\hline Age groups (in years) & $<15$ & $15-30$ & $31-45$ & $46-60$ & $>60$ & Total \\
\hline \multicolumn{7}{|l|}{ Post-Operative event } \\
\hline Uneventful & 2 & 43 & 20 & 10 & 0 & 75 \\
\hline Complications & 0 & 3 & 5 & $12\left(11 \mathrm{M}^{*}+1 \mathrm{~F}^{*}\right)$ & 1 & 21 \\
\hline Death & 0 & 0 & 0 & 1 & $6\left(4 \mathrm{M}^{*}+2 \mathrm{~F}^{*}\right)$ & 7 \\
\hline
\end{tabular}

(*M-Male; F-Female)

perforative peritonitis was more common in male and most common pathology was peptic perforation due to acid peptic disease, in their study. ${ }^{11}$ Possible reason thought for this finding may be smoking and alcohol intake, which is more frequent among Indian men population than in women, hence increasing the risk of perforation. In our

Asian Journal of Medical Sciences | Nov-Dec 2018 | Vol 9 | Issue 6 


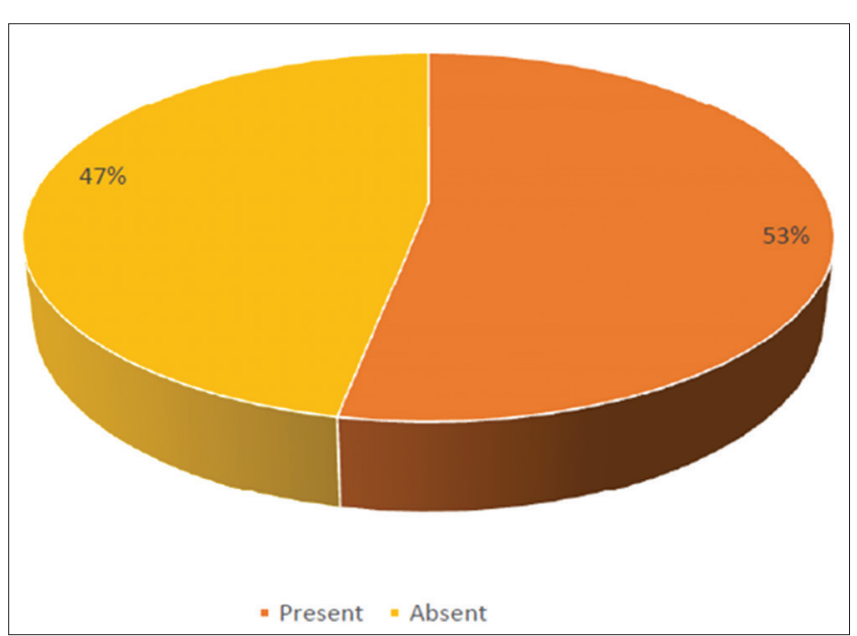

Figure 5: Distribution of patients with history of Peptic Ulcer Disease

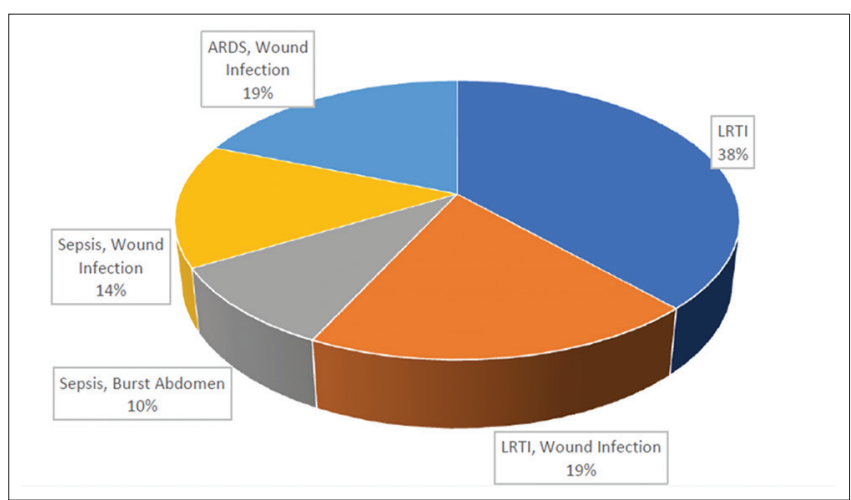

Figure 6: Complications reported in PPU patients in post-operative period ( $n-21)$; excluding Death

study, patients presented with age ranging from 14 to 72 years with the mean patient age of 36.3 years and standard deviation being 14.3 (36.3 \pm 14.3). Most of the patients $(45 \%)$ were from the age group of 15 to 30 years followed by $24 \%$ patients in the age group of 31 to 45 years. In study conducted by Nuhu et al. age range was of $18-77$ years and a mean age of $45.49 \pm 14.46$ years. ${ }^{3}$ Another study was conducted by Ozalp $\mathrm{N}$ et al. on patients the age group of 17 to 80 years (mean 63 years, median 68 years). ${ }^{12}$ In the study conducted by Meena et al, ${ }^{4}$ the mean age of patients was $39.13 \pm 15.29$ years and in study by Dodiyi-Manuel ${ }^{15}$ study patient ages ranged from 24 to 65 years with a mean of $42.1 \pm 12.3$ years and the peak age incidence was at the $3^{\text {rd }}$ decade which was approximately near to our study findings. Probably Hpylori infection which is most common cause for perforations in developing countries was the contrast in our study as compared with other studies. Chalya et al. found that perforation of peptic ulcer remains a frequent clinical issue predominantly affecting young male population not known to suffer from PUD. Simple closure with omental patch followed by Helicobacter pylori eradication was found to be effective with excellent results in majority of survivors despite patients' late presentation. ${ }^{13}$
In this study about $40 \%$ of the participants resided in Urban slum area and $86 \%$ of the patients were belonging to lower socioeconomic status which was found to be consistent with findings that the prevalence of $H$. pylori varies largely on the overall standard of living. In developing countries of the world, $80 \%$ of the population may be infected by the age of 20. Transmission of H. pylori occurs from person to person, followed by an oral-oral or fecal-oral route. Al-Marsoumi et al. ${ }^{14}$ concluded that Helicobacter pylori infection was the most common finding in the lowest socio-economic class $(85 \%)$. Developing countries shows a higher percentage of $H$. pylori infection.

In our study mortality rate of $6.9 \%$ (7 patients) was reported out of total 102 patients. However, mortality rate was seen directly proportional to delay in presentation and the presence of shock at the time of presentation. Highest mortality was reported in patients presenting after 4 days of onset of symptoms. All the patients attending Emergency department after 5 days of onset of symptoms presented with shock and among these patients $75 \%$ of the patients expired. Sushamaetal. ${ }^{15}$ also showed similar mortality rates in their study. However, in study by Buck DL et al. ${ }^{16}$ the mortality was found to be as high as 17 percent. ${ }^{15}$ In study by Thorsen $\mathrm{K}$ et al. the overall mortality rate was $16.3 \%{ }^{17} \mathrm{Bae} \mathrm{S}$ et al. showed a mortality rate of $3 \%$ in Korean Population. ${ }^{18}$ Lee FY et al. found mortality to be around $7.8 \% .{ }^{1}$ Association of delayed presentation with increased mortality can be explained by the fact that with increased duration localized peritonitis progressed to generalized peritonitis, sepsis sets in and overall patient's immunity level decreases all compounded by patient co-morbidities. Our study demonstrated definite relationship between the size of perforation and mortality with perforations more than $1 \mathrm{~cm}$ having mortality rate of $55.5 \%$, with size of perforations ranging from as small as $0.2 \mathrm{~cm}$ to as large as $1.5 \mathrm{~cm}$ consistent with Nuhu et al study ${ }^{2}$ (range 0.5 to $1.5 \mathrm{~cm}$ ). Higher mortality in patients with larger perforations $(>1 \mathrm{~cm})$ was explained by higher chances of leakage and greater chances of shock.

In the study, of 102 patients only 33 patients were found to be on ulcerogenic medications and out of the 33 patients 29 patients (88.7\%) predominantly were found to be on NSAIDs followed by a combination of NSAIDs and steroids. Most of the patients belonged to age groups above 45 years and suffered from Cardiovascular, Neurological or Rheumatologic co-morbidities for which they have been prescribed these drugs. Zelickson MS et al. found that NSAID use was confirmed in $68(53 \%)$ patients of the 128 patients they studied. ${ }^{19}$ Konturek SJ et al. ${ }^{20}$ claimed that NSAID alone was used by $6.2 \%-12.7 \%$ of ulcer patients out of 5967 patients. Other Studies by Gisbert JP et al. ${ }^{15}$ 


\begin{tabular}{|c|c|c|c|c|c|c|}
\hline Age groups (in years) & $<15$ & $15-30$ & $31-45$ & $46-60$ & $>60$ & Total \\
\hline \multicolumn{7}{|l|}{$\begin{array}{l}\text { Duartion of hospitals } \\
\text { stay (in days) }\end{array}$} \\
\hline $1-5$ & 2 & 36 & 13 & 1 & 0 & 52 \\
\hline $5-10$ & 0 & 10 & 11 & 16 & 0 & 38 \\
\hline $11-15$ & 0 & 0 & 1 & 3 & 0 & 4 \\
\hline$>15$ & 0 & 0 & 0 & 2 & 0 & 2 \\
\hline
\end{tabular}

and Henry et al. ${ }^{16}$ suggested strong association of PPU with the use of NSAID.

In this study we reported the relationship between PPU and some form of addiction particularly smoking. Only 12 patients out of 102 patients had no history of any addiction. 53 patients $(59 \%)$ were chronic smokers; 22 patients $(24 \%)$ were both smokers and alcoholic; 9 patients were Glue sniffers and 6 patients $(7 \%)$ were alcoholic. Asefa $\mathrm{Z}$ et al. ${ }^{21}$ documented history of smoking in $82.8 \%$ of their study population. Koto Kamsir et al. ${ }^{22}$ provided definitive conclusions of a relation between alcohol consumption and PPU. Studies like Reinbach et al. ${ }^{23}$ and Svanes et al..$^{24}$ have not only implicated smoking in the pathogenesis of PPU and PUD but smokers been found to have ulcers more frequently than non-smokers. The mechanism responsible for increased ulcer diathesis in smokers is unknown. Theories have included altered gastric emptying, decreased proximal duodenal bicarbonate production, increased risk for $H$. pylori infection, and cigarette-induced generation of noxious mucosal free radicals. Most patients with PPU have Helicobacter pylori $(\mathrm{H}$. pylori) infection. In this study, $72 \%$ of the total patients tested positive for $\mathrm{H}$ pylori infection, it was mostly uncommon in age groups of 46 to 60 years and completely absent in elderly age group ( $>60$ years). In $\mathrm{Ng}$, Enders K. W. et al. ${ }^{25}$ study of 129 patients with PPU, $104(81 \%)$ were found to be infected by $H$. pylori.

Uneventful recovery was reported in $74 \%$ of the patients. However, $20 \%$ patients had complications like respiratory tract infections (LRTI -38\%); wound infections (19\%); sepsis and burst abdomen (10\%); ARDS with wound infection $(19 \%)$. Sepsis and other contributing factors were responsible for death of 6 patients $(7 \%)$. Nuhu et al. showed major complications like wound infection in $14(34.1 \%)$, postoperative fever in $16(39.0 \%)$ and prolonged ileus in 15 (36.6\%). Death of 7 participants was reported with mortality rate of $17.1 \%$. Another study by Lee et al. showed the mortality rate of $7.8 \%(34 / 436)$, and 89 patients $(20.4 \%)$ had postoperative complications similar to this study. In this study, the average duration of stay at hospital was 6.3 days ranging from 4 to 18 days. In Nuhu et al. noted the average duration of hospital stay of
10 days (range 8-36). Prolonged hospital stay was found to be associated with post-operative complications. ${ }^{25,26}$

\section{CONCLUSION}

Perforated peptic ulcer is a common finding among male population in second and third decade of their life with patients living in rural and urban slum commonly affected. Most common predisposing factor for PPU among younger population was addictions like Smoking or Alcohol intake. Among the elderly patients, intake of ulcerogenic medications like NSAID and steroids was the most common predisposing factor for PPU. Among patients of non-NSAID associated PPU, Helicobacter pylori infection was the major cause in the pathogenesis of PPU. The important factors clearly deciding the fate of the patients with PPU are early diagnosis, resuscitation with fluids, correction of shock; timely presentation and early surgical intervention. Old age, female sex, delays in presentation, presence of shock, large perforation and presence of co-morbid factors were found to be associated with increased mortality.

\section{Limitations}

This was an observational descriptive study and vulnerable to poor quality of records maintained as noted in the incomplete dataof the total patients managed. Comparatively categorical statements on outcomes of therapeutic management are not available. Randomized prospective clinical studies are needed in future.

\section{ACKNOWLEDGEMENT}

Post-graduate Trainees and all staffs of Department of Surgery, R.G.Kar Medical College, Kolkata.

\section{REFERENCES}

1. Møller MH, Adamsen S, Thomsen RW, Møller AM, and the Peptic Ulcer Perforation (PULP) trial group. Multicentre trial of a perioperative protocol to reduce mortality in patients with peptic ulcer perforation. Br J Surg 2011; 98: 802-810.

2. Lee FY, Leung KL, Lai BS, Ng SS, Dexter S and Lau WY. 
Predicting mortality and morbidity of patients operated on for perforated peptic ulcers. Arch Surg 2001; 136(1):90-94.

3. Nuhu A and Kassama Y. Experience with acute perforated duodenal ulcer in a West African population. Niger J Med 2008; 17(4):403-406.

4. Meena LN, Jain S and Bajiya P. Gastrointestinal perforation peritonitis in India: A study of 442 cases. Saudi Surg J 2017; 5:116-121.

5. Aggarwal N, Saha S, SrivastavaA, Chumber S, DharAandGarg S Peritonitis: 10 years' experience in a single surgical unit. Trop Gastroenterol 2007; 28:117-120.

6. Jhobta RS, Attri AK, Kaushik R, Sharma R and Jhobta A. Spectrum of perforation peritonitis in India - Review of 504 consecutive cases. World J Emerg Surg 2006; 1:26.

7. Lau JY, Barkun A, Fan DM, Kuipers EJ, Yang YS and Chan FK. Challenges in the management of acute peptic ulcer bleeding. Lancet 2013; 381: 2033-2043.

8. Horowitz J, Kukora JS and Ritchie WP. All perforated ulcers are not alike. Ann Surg 1989; 209: 693-696.

9. Hirschowitz BI, Simmons J and Mohnen J. Clinical outcome using lansoprazole in acid hypersecretors with and without Zollinger-Ellison syndrome: a 13-year prospective study. Clin Gastroenterol Hepatol 2005; 3: 39-48.

10. Gupta SK, Gupta R, Singh G and Gupta S. Perforation peritonitis: A two year experience. JK Sci 2010; 12:141-144.

11. Patel $P$ and Suryadeep B. Prospective study of 50 cases of perforative peritonitis a single centre experience; International Surgery Journal; Int Surg J 2017; 4(8):2782-2785.

12. Dodiyi-Manuela A, Wichendu PN and Enebeli VC. Presentation and Management pf perforated Peptic Ulcer disease in a tertiary centre in South Nigeria. J West Afr Coll Surg 2015; 5(3): 36-48.

13. Phillipo C, Joseph M, Mheta K, Mabula M, Hyasinta J, Rodrick K, et al. Clinical profile and outcome of surgical treatment of perforated peptic ulcers in Northwestern Tanzania: A tertiary hospital experience. World J Emerg Surg 2011; 6: 31.

14. Al-Marsoumi AM and Jabbo NS. Risk factors in perforated peptic ulcer disease: Incidence and relation to morbidity and mortality. Mustansiriya Medical Journal 2013; 12(1): 35-44

15. Surapaneni S, Rajkumar S and Vijaya Bhaskar Reddy A. The Perforation-Operation time Interval; An Important Mortality
Indicator in Peptic Ulcer Perforation. J Clin Diagn Res 2013; 7(5): 880-882.

16. Buck DL, Vester-Andersen M and Møller MH. Accuracy of clinical prediction rules in peptic ulcer perforation: an observational study. Scand J Gastroenterol 2012; 47(1):28-35.

17. Thorsen K, Søreide JA, Kvaløy JT and Glomsaker T and Søreide K. Epidemiology of perforated peptic ulcer: Age- and gender adjusted analysis of incidence and mortality. World $\mathrm{J}$ Gastroenterol 2013; 19(3): 347-354.

18. Bae S, Shim KN, Kim N, Kang JM, Kim DS, Kim KM, et al. Incidence and short-term mortality from perforated peptic ulcer in Korea: a population-based study. J Epidemiol 2012; 22: $508-516$

19. Zelickson MS, Bronder CM, Johnson BL, Camunas JA, Smith $\mathrm{DE}$, Rawlinson $\mathrm{D}$, et al. Helicobacter pylori is not the predominant etiology for peptic ulcers requiring operation. Am Surg2011; 77: 1054-1060.

20. Konturek SJ, Bielaoski W, Płonka M, Pawlik T, Pepera J, Konturek PC, et al. Helicobacter pylori, non-steroidal antiinflammatory drugs and smoking in risk pattern of gastro duodenal ulcers. Scand J Gastroenterol 2003; 38(9):923-930.

21. Asefa $Z$ and Geyesus A. Perforated peptic ulcer disease in Zewditu Hospital. Ethiop Med J 2012; 50(2):145-151.

22. Kamsir K, Asrul A and Muradi A. Characteristic of Gastric Perforation Type and The Histopathology at Haji Adam Malik General Hospital Medan-Indonesia.Bali Medical Journal 2016; 5(1): 166-168.

23. Doll R,Peto R, Wheathly K, Gray R and Sutherland I. Mortality in relation to smoking: 40 years' observations on male British doctors. BMJ 1994; 309:901.

24. Svanes C, Søreide JA, Skarstein A, Svanes BT, Svanes K and Søreide O. Smoking and ulcer perforation. Gut 1997; 41:177.

25. Enders KW Ng, Lam YH, Joseph JY Sung, Yung MY, To KF, Angus CW Chan, et al. Eradication of Helicobacter pylori Prevents Recurrence of Ulcer After Simple Closure of Duodenal Ulcer Perforation Randomized Controlled Trial. Ann Surg 2000; 231(2): 153-158.

26. Manfredini R, De Giorgio R, Smolensky MH, Boari B, Salmi R, Fabbri D, et al. Seasonal pattern of peptic ulcer hospitalizations: analysis of the hospital discharge data of the Emilia-Romagna region of Italy. BMC Gastroenterol 2010; 10: 37.

\footnotetext{
Authors Contribution:

BCG- Review of literature, manuscript preparation and data collection; AG- Concept and design of the study, manuscript preparation, statistical analysis, data interpretation, critical revision of manuscript.

Work attributed to:

Department of General Surgery, R.G .Kar Medical College, Kolkata.

Orcid ID:

Dr.Bikash Chandra Ghosh- (1) http://orcid.org/0000-0001-5708-9243

Dr. AmbarGangopadhyay- (D) http://orcid.org/0000-0003-2160-9256

Source of Support: R. G. Kar Medical College, Kolkata.(All surgeries conducted in this Government Medical College), Conflict of Interest: None declared.
} 